\title{
Interpersonal Functions of EFL Teachers' Evaluative Discourse
}

\author{
Junming Lai \\ Post-doctoral Workroom, China National Institute for Education Research, Beijing 100088 \\ E-mail: ljmxbh2005@yahoo.com.cn
}

\begin{abstract}
As an important dimension of interpersonal function in SFL, appraisal has attracted a lot of attentions from the linguists home and abroad. This thesis is an attempt to analyze the interpersonal functions of EFL teachers' evaluative discourse with in the framework of Palladian Systemic-functional Grammar (SFG) and Martin's Appraisal theory. The aim for the study is to construe an analytical model for the interpersonal functions of teachers' evaluative discourse by analyzing the patterns of evaluative discourse and evaluative strategies.
\end{abstract}

Keywords: SFL, Appraisal, Classroom discourse

Systemic-functional linguistics (SFL), as its name suggests, considers function and semantics as the basis of human language and communicative activity. Unlike structural approaches that privilege syntax, SEL-oriented linguists begin an analysis with social context and then look at how language acts upon, and is constrained and influenced by this social context. Context id a very important part of SFL theory, and is also necessary in the discourse analysis, as P.R. White (2001:3) proposes that "across all the discourse domains it proved necessary to explore in what contexts, by what linguistic means and to what rhetorical ends writers pass values, attribute their propositions to outside sources or moralizes their utterance".

Systemic-functional linguists suggested that the notion of context primarily comprises two levels: one is context of culture which is also called genre, considering language as a system; the other is context of situation, encoded in register, which refers to context for the particular instances and takes language as processes of text. To be specific, genre is concerned with how people use language to achieve culturally appropriate goals, and register is concerned with how people use language is some particular situations. Context of situation is a key concept in Holliday's approach which obtains "through a systematic relationship between the social environment on the one hand, and the functional organization of language on the other" (Halliday \& Hasan, 1985:11).

Register is characterized with three main dimensions of variation: what is being talked about(field); the people involved in the communication and the relationship between them(tenor); and how the language is functioning in interaction, e.g. whether it is written or spoken(mode).In this chapter we will mainly discuss the context of situation or register and make an analysis of teachers' evaluative discourse in terms of Field, Tenor and Mode which "collectively constitute the register the register of a text" (Halliday\&Hasan,1985:11).

Partnerships in early teacher education between schools and universities appear to be both increasingly valued whilst being fatally restricted by institutional management models of partnership that are characterized by a strong reliance on performance-based assessments and an absence of reflective professional dialogue .This militates against understanding how student teachers best learn about teaching and restricts or forecloses on discussions of personal identity formation in teaching in either schools or universities.

A number of organizations have proposed setting standards for teachers' professional development the guiding principles behind these ideas are summarized in the sidebar in the previous section. Standards might help improve the quality and efficiency of professional development. However, while these proposals are useful for discussion, it is important that state and local policymakers engage teachers in the process of setting standards for states or diarists. Teachers have a great deal of insight into what has made professional development effective or ineffective in the past, and will be more likely to support changes to the current system if they have been a significant part of the improvement process.

Promising Policy Options

To make professional development more effective and more consistent with the guiding principles outlined in the sidebar in the previous section, policymakers need to be clear about the problems they are trying to solve and about the conditions under which teachers are likely to change their practice. They must also be more concerned about the quality and character of experiences provided for teachers. And, given the scarcity of resources, they must strive to be efficient, to leverage additional resources, and to make full use of expertise already in the system.

Fortunately, some policymakers and practitioners have come up with new approaches that are promising, though 
we know little about their costs or effects as yet.

These approaches to teacher professional development are consistent with the guiding principles outlined in the sidebar in the previous section and share some common characteristics. The respect the expertise of accomplished teachers. They are integrated with teachers' work. They are based on current research on teaching and learning. They recognize teachers as a valuable source of information regarding effective professional development and include them in its design and implementation. The examples below are good starting points for incorporating these ideas.

Joint Work and Job Enrichment

Joint work refers to shared responsibility for tasks, such as in team teaching, curriculum committees, or other jobs that create interdependence among teachers and require cooperation. Joint work promotes learning on the job because it provides opportunities for productive exchange among teachers and reflection about practice. Job enrichment refers to the expansion of teachers' work in ways that require new skills, such as the shooting of portfolios in Vermont or serving as mentors to beginning teachers in Connecticut. These new responsibilities include opportunities for teachers to discuss their practice and share ideas.

Teacher Networks

Teacher networks tend to focus on specific subject-matter and seek to deepen teachers' understanding of content and their facility with new teaching strategies. They offer teachers access to a "professional community" in which their expertise and experience are respected and where they can be active participants in professional discourse about improving practice. Networks have high credibility with teachers, and appear to have positive effects on their motivation, Knowledge of pedagogy and subject-matter, willingness to take risks, and commitment to improvement. The National Writing Project, Urban Math Collaborative, California's subject-matter collaborative and Vermont's portfolio networks are examples of teacher networks.

Collaborations between Schools and Colleges

Professional development opportunities cannot be provided in sufficient intensity and for sufficient numbers of teachers unless the schools and colleges work together. Some organizations, such as the Carnegie Corporation of New York, Ford Foundation, Knight Foundation, the Pew Charitable Trusts, and the Rockefeller Foundation are actively promoting and supporting partnerships between colleges and schools. While these initiatives vary in size and focus and remain quite fragile, dependent in many instances on external funding and often operating at the margins of the institutions, they hold great promise for strengthening professional development. As current reforms require teachers to deepen their knowledge of subject-matter, it is important that these initiatives involve liberal arts faculty as well as those in schools of education.

Professional Development (or Practice) Schools

Professional development schools are a special form of collaboration between public schools and higher education. The Association for Supervision and Curriculum Development has documented several hundred of these institutions which are roughly analogous to teaching hospital. While much attention has been given to their potential role in the pre-service preparation of teachers, they also could play an important role in professional development. They could bring both novice and experienced teachers together with university clinical faculty in a professional setting to improve their practice through observation, low-risk experimentation, reflection and coaching.

\section{National Board Certification}

The National Board of Professional Teaching Standards has worked with teachers and national teacher organizations to establish standards and assessment procedures for recognition of exemplary teachers. The Board hopes that teachers who achieve "national board certification" will be given responsibilities commensurate with their abilities, such as mentoring beginning teachers or developing curricula, and that local policymakers will use its standards to guide their professional development professional development for teachers as it requires them to document their practice, reflect on their strengths and weaknesses, and demonstrate specific knowledge and skill.

Teachers as Researchers

Increasing numbers of teachers are conducting research in their classrooms and schools in cooperation with their colleagues and university faculty. While some of these research projects are defined by academic interests, many are directed at problems identified by the teachers themselves. There is considerable evidence that involving teachers in research can stimulate discussion, help organizations define problems, and lead to changes in practice and policy. 
Despite Wenglinsky's promising finding, a variety of quantitative and qualitative studies over the years indicate that change, at least as promoted by an "external" factor such as professional development, is a complicated process.

Change is slow. Even when professional development extends over several years, with multiple opportunities for learning (Short\&Echevarria, 1999), change is a process occurring over time that requires support (Imel, 2000; Joyce, 1983).

Change requires support. Change requires much more intensive learning support than teachers generally receive in the type of professional development they usually experience: "mandated district-sponsored staff development, consisting of a menu of training options designed to transmit a specific set of ideas, techniques, or materials to teachers"

Change is not always linear.Fullan (1990) argues that there is an "implementation dip" as teachers tries new actions, before they have fully integrated the new idea, and this is a period of stress and anxiety for teachers.

Outside the personal identity projects described here, the experienced university mentors teach methods and postgraduate curriculum courses at the University of Melbourne and visit students in schools to advise on and assess their teaching practice during the three teaching rounds, each of 3 weeks in different schools. The school mentors may supervise single students during one of these rounds in which they would advise students in the same areas in more restricted context. Whilst the standard mentoring is conducted separately, we would, from both positions, say we are concerned with the transformation of the student teacher's work and our own work from following recommended practice to the achievement of a committed grammar, or way of skilled talking and acting, as a teacher.

The big theoretical picture is: the individual and society, practice and structure, agency and structure, socialization and social reproduction. These are coupled categories depicted in different ways by different theorists as dialectically reproducing and transforming one another in the unbroken process of "structure". Yet we need to identify the means by which the everyday shaping and reproduction of self and society, of individual and institution, come to be expressed as specific structure-influenced practices occurring at determinate locations in time and space-in detailed situations. We need to get a tighter grip on precisely how the everyday functioning and reproduction of particular cultural, economic, and political institutions are bound up with specific actions, knowledge build-up, and biographies of particular individual students and colleagues. A "sense of place" and "structure of feeling" underpin, in essential ways, continuity in individual experience and mental complexity of the roles and responsibilities of practitioners and academic staff in teacher education and research is emphasized in this structure that students experience in their personal identity formation as teachers.

In this paper the professional personal identity project is project is proposed and illustrated as a possible social-psychological framework for pedagogical partnerships in teacher education between students, and their school and university superiors. Hare's model of identity formation (Figure1) consists of two axes-the public (interment)/private (instrumental) and the quadrants are traversed from the public/collective direction by four types of operation: Appropriation, Transformation, Publication and Conventionalization. We can think of the operations as a learning cycle in which the student teacher appropriates knowledge and skills, internalizes and adapts them, creates products or performances by which these processes are made public (assessed in various way by colleagues)and is then rewarded-or otherwise-by some kind of collegial/public recognition.

Recently the National Partnership for Excellence and Accountability in Teaching (USA) has presented 9 so-called design principles, and refers to some examples and to the research literature supporting the different principal. Hereafter, a summary of those nine principles is presented.

Design principle 1

The content of professional development focuses on what students are to learn how to address the different problems students may have in learning the problem.

Design principle 2

Professional development should be based on analyses of the difference between (a) actual student performance and (b) goals and standards for student learning.

Design principle 3

Professional development should involve learners in the identification of what they need to learn and, when possible, in the development of the learning opportunity and/or the process to be used.

Design principle 4 
Professional development should be primarily school-based and built into the day-to-day work of teaching (or integral to school operation).

Design principle 5

Professional development should be organized around collaborative problem solving.

Design principle 6

Professional development should be continuous and on-going, involving follow-up and support for further learning, including support from sources external to the school that can provide necessary resources and new perspectives.

Design principle 7

Professional development should incorporate evaluation of multiple sources of information on (a) outcomes for students and (b) the instruction and other processes that are involved in implementing the lessons learned through professional development.

Design principle 8

Professional development should provide opportunities to gain an understanding of the theory underlying the knowledge and skills being learned.

Design principle 9

Professional development should be connected to a comprehensive change process focused on improving student learning.

These nine principles do overlap to some extent, but combined in a balanced way, they provided a conceptual background and at the same time empirically validated recommendations for effective professional development of teachers.

The complementarily between teacher's professional development and the concomitant organizational arrangement (or in more general terms organizational development) can be illustrate by exploring in more detail some of the characteristics of the design principles.

Teachers were asked about the outcomes of their professional development experience in relation to gains in content knowledge and in skills for incorporating new knowledge into instruction. Fifteen of the 18 teachers ranked the value of new content knowledge and new knowledge about teaching skills as extensive, as distinct from moderate or limited. Project-STIR (Science Teachers in Industry and Research) teacher reported that they had learned more about geology, DNA, the use of the graphing calculator, and how to work across disciplinary areas. The Reading Recovery teachers reported that they had learned more about how to teach reading, to record students' reading behaviors, and to use this information for instructional purposes. Two science teachers and one reading teacher described gains in both content knowledge and teaching skill as moderate, but still cited particular areas, such as the use of technology, as additional knowledge gained.

In the interview teachers were asked about opportunities for interaction with program participants and other professionals, a feature of high-quality professional development programs. Although neither program was exclusively school-based, all nine science teachers and seven reading teachers reported that they had many opportunities to interact with program colleagues, which they regarded positively.

\section{Field of the teachers' evaluative discourse}

Field is concerned with what is happening in the discourse, what is the nature of the social interaction taking place, what is it that the participants are engaged in, and in which language figures as an essential component. Central to it is the communicative purpose of the discourse, a decisive factor to identify a genre or discourse as it is (Swales, 1990; Bhatia, 1993; Martin\&Rose, 2003).In the classroom situation, the purpose of the teachers' use of evaluative discourse is to interact with students and encourage students' better and greater involvements to fulfill their teaching aims and build up a good relationship with students. Thus the entire teaching or learning can be seen ad a communication, a kind of communicative activity taking place in the classroom, and the discourse or language is just a tool or resource to realize that communication.

The nature of the interaction between teachers and students is trying to build up a kind of relation; evaluation is just a means to achieve this aim. Teachers use some kinds of evaluative strategies and discourse to instruct students' class performances and help with students' learning, as the same time a kind of interpersonal relationship is also built up. Different evaluative discourse and strategies can result in different relations, it's necessary for the teachers to pay attention to the evaluative discourse they use in the classes. 


\section{Tenor of the teachers' evaluative discourse}

Tenor is concerned with who is taking part, what are the social roles and relationships of participants, what are the social roles and relationships of participants, what are the status and roles of the participants, As far as tenor is concerned, basically there are three participants in the classroom discourse: teacher, students and the objectives of evaluation. Teacher is usually the person who evaluates and holds the discourse power in the class, and students are generally the persons who are evaluated in class and comparatively passive in the discourse interaction.

The classroom is not only a place of formal or institutional learning but also a social and affective environment in its own right, one where teachers and pupils negotiate relationships and identities (Yao, 2007). So relationship between teachers and students is important for us to understand the functions of the teachers' evaluative discourse, factor of tenor can explain the purposes of teacher' evaluative on students and how teachers make a good use of the evaluative discourse. Pontoon (1990; quoted in P.R.White, 2001) provided a model of the interpersonal relationship with respect to an aspect of social context Tenor which is concerned with the constitution of social roles and relationships and the negotiation of these roles and relationships by speakers. Under his model social relationships may be organized by three dimensions-power/ statue, contact and affect.

Martin \& Rose(2003)propose that power and solidarity are two key variables in tenor which are the" vertical and horizontal dimensions of interpersonal relationship", both Pontoon's model and Martin's proposals can be applied to the analysis of the tenor of the teachers' evaluative discourse. This study intends to take Martin's power and solidarity relations.

\subsection{Power relation between teacher and students}

The power variable is concerned with two factors, equality and inequality, which can be defined by generation, gender, ethnicity, incapacity and class .Noonan(1993)proposed that special features of classroom discourse include unequal power relationships which are marked by unequal power opportunities for teachers and students to nominate topics, take turns at speaking etc.

The relationship between teacher and students at the first time is unbalanced, can not be equal no matter from the point of view of generation, gender and incapacity or from the perspective of traditions coming down from the ancient times in China or the world. Teacher usually has higher status in class, and is more active in the class. He holds the discourse power and tends to control the class in hope of students' following his instructions. While the students are comparatively passive in class with lower status, their discourse power is under the control of the teacher, they follow teacher's instructions although sometimes some students don't listen to the teacher. Power relation between teacher and students can be illustrated by the following figure1:

Although this kind of relationship between teacher and students which is demonstrated in the classroom as that teacher is a dominating role and students are the passive roles is not advocated in today'EFL teaching, power relation is necessary and works well to some extent in the teaching and learning process. Without power relation classes will be out of control and the effectiveness and efficiency of classroom teaching and learning cannot be guaranteed. However, power relation can not work well alone, another relationship is also necessary in the class, that's solidarity relation.

\subsection{Solidarity relation between teacher and students}

The solidarity variable is concerned with alignment between participants; the degree of solidarity is determined by two factors: the range and frequency of common activities and shared feelings about the value of social action (Martin \& Rose, 2003: 249). Pontoon (1985; quoted in White, 2001) in his model of interpersonal relationship observes that solidarity involves degree of contact and affective involvement.

As far as contact is concerned, the classroom teaching activities provide a lot of chances for the teacher and students to contact with each other. From this point of view, we can say the contact between teachers and students is rather frequent and familiar. However, with such a frequent contact, teachers may not set up a familiar and harmonious relationship with the students. That's because there are many other variables except the degree of contact. Evaluation is one of the means which can help teachers to build up and maintain a comparatively good relationship with students. Teachers can explore different evaluative strategies and utterances to negotiate relationship with students, that relationship is solidarity relation which implies that teacher and students can share same feelings or values for something. And for the solidarity, teachers should try to be an image of positive rather than negative, and work as a helper which can give encouragements and confidence to the students in their EFL learning.

As far as affective involvement is concerned, communication is not only an exchange of ideas and thoughts but 
also an exchange of feelings and affections. In the classroom teaching communication takes place between teacher and students, teacher teaches knowledge and students make responses to what they learn and feed back whether they known or not, that's an exchange of knowledge. However, in the classes, they also exchange feelings and affections with each other, for an instance, teacher encourages students in their learning using some evaluative discourse such as Great, you're excellent, you did a very good job. These evaluative expressions can be considered as teachers' negotiating solidarity relation with students. From the perspective of a high degree of frequency of contact between teachers and students, it can be inferred that the affective involvement is relatively high.

Power and solidarity relation are interdependent. Solidarity relation between teachers and students is based on the power relation between them, and power relation is strengthened and implicated by solidarity relation.

Mode is concerned with the symbolic organization of the text, rhetorical modes (persuasive, expository etc), and the channel of communication, such as spoken or written, monologist or dialogic, visual contact, computer-mediated communication, telephone, F2F etc. In other words, mode of discourse refers to the mediums and the channels adopted in language activities. Teachers' evaluative discourse can be either in spoken form or written, it may be spoken, when teachers are making utterances of evaluation of students; it may be written, when teachers are making some evaluation on students' writing tasks in their exercises books. This study concerns the spoken form of the teachers' evaluative discourse, the data collected for this study are teachers' utterances made in the EFL classes and all in the spoken form.

\section{Summary}

In this chapter we've discussed the context of teachers' evaluative discourse, two dimensions of context are mentioned, of which register is the focus of this chapter. As for register, three factors are discussed in details in terms of field, tenor and mode. Among these three factors, tenor mainly determines the interpersonal meaning, refers to social role-relationship and the goal of language activities. In classroom, teacher and students are granted different social identities. Power is interrelated with socially constructing social identities and power has a great effect on the degree of intimate. Power is often discussed in studies of classroom language and literacy events either directly or by references to related topics such as equity, democracy, freedom and so forth. While in classroom, teachers often negotiate solidarity relations with students. Solidarity can help teacher build up a relatively democratic and harmonious relation with students. The interpersonal relationship is switched by these two factors: power and solidarity, which are the key and primary ones existing in the classroom interaction between teachers and students.

\section{References}

Albright and Bailey. (1991). Focus on the Language Classroom. Cambridge: Cambridge University Press.

Brown, G. \&G. Yule. (1983/2000). Discourse Analysis. Cambridge/Beijing: Cambridge University Press/FLTRP.

Diane Hart. (2003). Authentic Access-Handbooks for Teachers. Beijing: China Industrial Press.

Eggins, S. \&D.Slade. (1997). Analyzing Casual Conversation. London: Chassell.

Gee, J.P. (2000). An Introduction to Discourse Analysis: Theory and Method. Beijing: Foreign Language Teaching and Research Press \& R out ledge.

Liebscher, G. \& Dailey-O'cain, J. (2005). Learner Code-switching in the Content-based Foreign Language Classroom. The Modern Language Journal89:234-247 


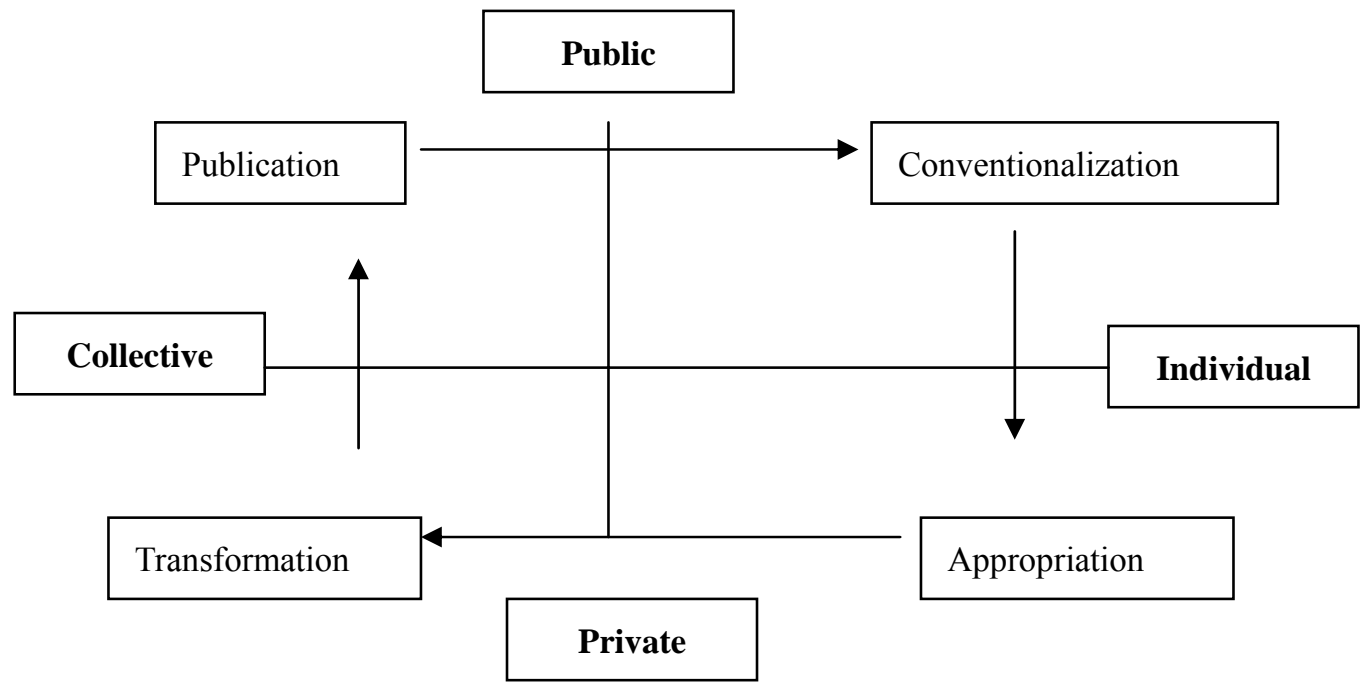

Figure 1. Model for the successful completion of personal identity projects for student teachers within the social world of the school. (After Harre, 1983)

\section{Effective professional development and organizational consequences}

\begin{tabular}{|l|l|}
\hline Professional development activities & Organizational arrangements \\
\hline -Focus on concrete classroom application & $\begin{array}{l}\text {-Specific agreements among teachers concerning the use of teaching } \\
\text { materials or methods }\end{array}$ \\
\hline $\begin{array}{l}\text {-Discussions about actual practice, rather than } \\
\text { descriptions of practices. }\end{array}$ & $\begin{array}{l}\text {-Shared decision-making and discussions about real changes and } \\
\text { try-outs in the classroom }\end{array}$ \\
\hline -Opportunities for observation, critique and reflection & $\begin{array}{l}\text {-Acceptance by teachers to visit classroom; } \\
\text {-Providing opportunities for collaboration; } \\
\text {-Providing time for collegial reflection }\end{array}$ \\
\hline -Opportunities for group support and collaboration & -Time for professional meetings and collective preparation time \\
\hline -Deliberate evaluation and feedback & $\begin{array}{l}\text {-By colleagues } \\
\text {-By the principal } \\
-B y \text { a department chair } \\
-B y \text { an external expert(creating collaboration with external } \\
\text { organizations })\end{array}$ \\
\hline
\end{tabular}

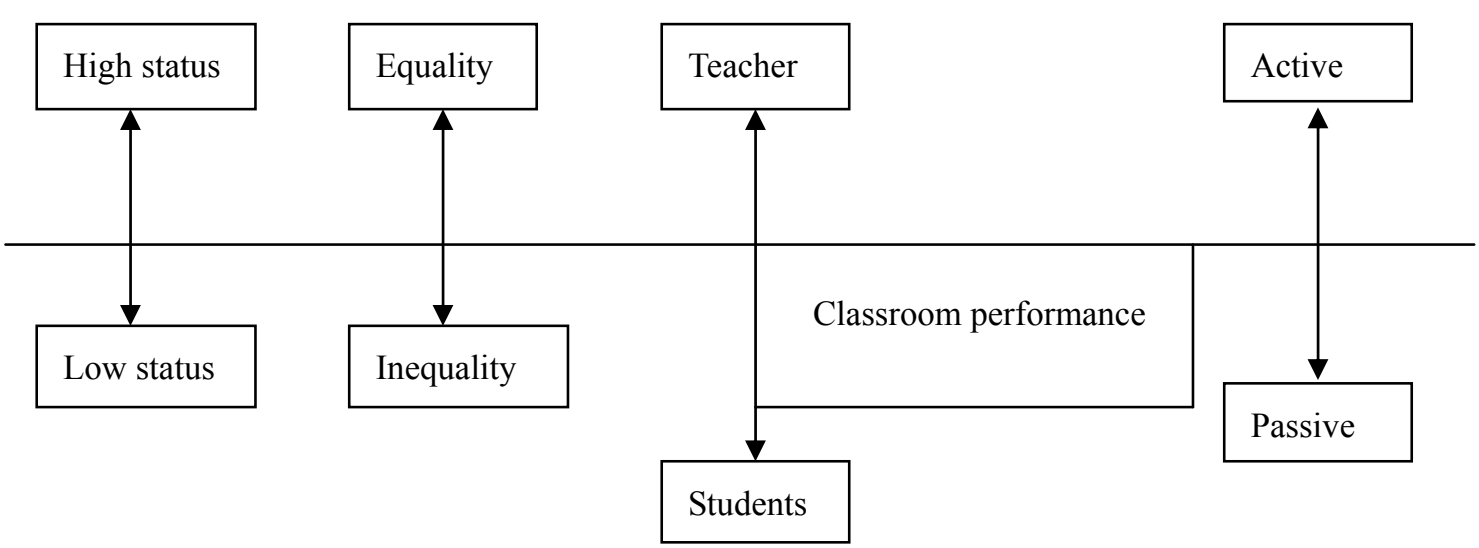

Figure 2. Power relation between teacher and students 